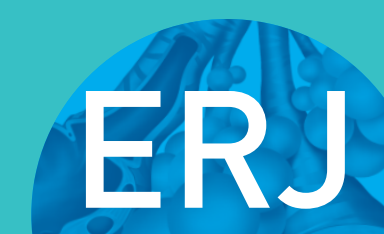

open research

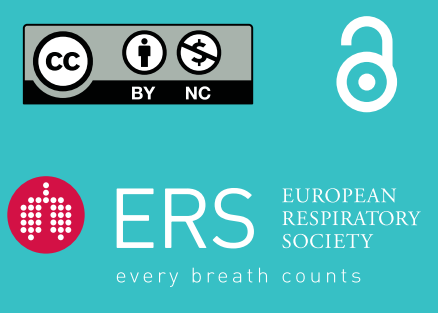

\section{COVID-PCD: a participatory research study on the impact of COVID-19 in people with primary ciliary dyskinesia}

\author{
Eva S.L. Pedersen (101, Eugénie N.R. Collaud ${ }^{1}$, Rebeca Mozun (1) ${ }^{1,2}$, \\ Cristina Ardura-Garcia (1) ${ }^{1}$, Yin Ting Lam ${ }^{1,2}$, Amanda Harris $\mathbb{C}^{3}$, Jane S. Lucas $\mathbb{(}^{3,4}$, \\ Fiona Copeland ${ }^{5}$, Michele Manion ${ }^{6}$, Bernhard Rindlisbacher ${ }^{7}$, \\ Hansruedi Silberschmidt ${ }^{8}$, COVID-PCD patient advisory group, \\ Myrofora Goutaki (10 ${ }^{1,9}$ and Claudia E. Kuehni (ib)
}

Affiliations: ${ }^{1}$ Institute of Social and Preventive Medicine, University of Bern, Bern, Switzerland. ${ }^{2}$ Graduate
School for Cellular and Biomedical Sciences, University of Bern, Switzerland. ${ }^{3}$ Primary Ciliary Dyskinesia
Centre, NIHR Biomedical Research Centre, University Hospital Southampton NHS Foundation Trust,
Southampton, UK. ${ }^{4}$ University of Southampton Faculty of Medicine, Academic Unit of Clinical and
Experimental Medicine, Southampton, UK. ${ }^{5}$ PCD Family Support Group, Ciliopathy Alliance, London, UK. ${ }^{6}$ PCD
Foundation, Minneapolis, MN, USA. ${ }^{7}$ Selbsthilfegruppe Primäre Ciliäre Dyskinesie, Steffisburg, Switzerland.
${ }^{8}$ Vorstand/Schriftführer des deutschen Vereins Kartagener Syndrom und Primäre Ciliäre Dyskinesie eV, PCD-
betroffen, Wetzikon, Switzerland. ${ }^{9}$ Paediatric Respiratory Medicine, Children's University Hospital of Bern,
University of Bern, Bern, Switzerland.

Correspondence: Claudia E. Kuehni, Institute of Social and Preventive Medicine, University of Bern, Mittelstrasse 43, 3012 Bern, Switzerland. E-mail: claudia.kuehni囚ispm.unibe.ch

ABSTRACT COVID-PCD is a participatory study initiated by people with primary ciliary dyskinesia (PCD) who have an essential vote in all stages of the research from the design of the study to the recruitment of participants, and interpretation and communication of the study results. COVID-PCD aims to collect epidemiological data in real-time from people with PCD throughout the pandemic to describe incidence of coronavirus disease 2019 (COVID-19), symptoms and course of disease; identify risk factors for prognosis; and assess experiences, wishes and needs.

The study is advertised through patient support groups and participants register online on the study website (www.covid19pcd.ispm.ch). The study invites persons of any age from anywhere in the world with a suspected or confirmed PCD. A baseline questionnaire assesses details on PCD diagnosis, habitual symptoms and COVID-19 episodes that occurred before study entry. Afterwards, participants receive a weekly follow-up questionnaire with questions on incident severe acute respiratory syndrome coronavirus 2 (SARS-CoV-2) infections, current symptoms, social contact behaviour and physical activity. Occasional thematic questionnaires are sent out focussing on emerging questions of interest chosen by people with PCD. In case of hospitalisation, patients or family members are asked to obtain a hospital report. Results are continuously analysed and summaries put online.

The study started recruitment on April 30, 2020, and 556 people with PCD completed the baseline questionnaire by November 2, 2020. The COVID-PCD study is a participatory study that follows people with PCD during the COVID-19 pandemic, helps to empower affected persons, and serves as a platform for communication between patients, physicians and researchers.

\section{@ERSpublications}

The COVID-PCD study is a longitudinal participatory study that follows people with \#PCD during the \#COVID19 pandemic, empowers people who have PCD, and provides a platform for communication between patients, physicians and researchers https://bit.ly/3fGi2DV

Cite this article as: Pedersen ESL, Collaud ENR, Mozun R, et al. COVID-PCD: a participatory research study on the impact of COVID-19 in people with primary ciliary dyskinesia. ERJ Open Res 2021; 7: 00843-2020 [https://doi.org/10.1183/23120541.00843-2020].

Received: 11 Nov 2020 | Accepted: 14 Nov 2020

Copyright $\odot$ ERS 2021. This article is open access and distributed under the terms of the Creative Commons Attribution Non-Commercial Licence 4.0. 


\section{Introduction}

The pandemic of coronavirus disease 2019 (COVID-19) caused by severe acute respiratory syndrome coronavirus 2 (SARS-CoV-2) has by November 2020 spread globally with $>47$ million infected people in over 200 countries and territories. The severity of COVID-19 ranges from asymptomatic to severe disease $[1,2]$, and elderly people and individuals with pre-existing chronic health conditions are at increased risk of a severe disease course [3-7]. COVID-19 has also been associated with impaired lung function after recovery, even in people without pre-existing health conditions $[8,9]$.

Primary ciliary dyskinesia (PCD) is a rare genetic multi-system disease that affects about 1 in 10,000 people. It leads to chronic upper and lower airway disease, laterality defects including congenital heart disease and other health problems [10-13]. While some patients are relatively mildly affected, others develop severe irreversible lung disease from an early age with repeated infections resulting in reduced lung function, bronchiectasis and sometimes oxygen dependency with some requiring lung transplantation [14-19]. We do not know how SARS-CoV-2 affects people with PCD and whether severity of PCD, age and other patient characteristics influence COVID-19 disease course. PCD registries and research databases are not designed for a longitudinal collection of patient-reported information on symptoms and health behaviour in real-time [20]. However, such data are needed to comprehensively understand the impact of SARS-CoV-2 on people with PCD. Patient-reported data are also essential to understand how public health measures that aim to reduce the spread of COVID-19 are adopted by people with PCD, and how the pandemic affects their life and medical care. During the early phase of the pandemic (March and April, 2020), people with PCD all over the world were worried and desperate to understand the effects of SARS-CoV-2 on persons with this rare disease. Given the lack of evidence, patient support groups approached researchers and proposed to set up a study together.

Research projects that focus on rare diseases can be challenging due to the limited number of people with the disease and their geographical dispersion [21]. It is therefore important to make the study as relevant as possible to the participants and ensure that participation is feasible. This can be helped by using a participatory approach in which study participants are engaged in all stages of a research project from the design of the study to shaping the content and interpreting results. Participatory research methods have been associated with better networking between participants, higher relevance for affected people, patient empowerment and higher participation rates [22-24]. COVID-PCD has been designed as a collaboration of epidemiologists, healthcare specialists and people with PCD. It is a longitudinal study aiming to collect data in real-time on health, healthcare, behaviour and psychosocial aspects from people with PCD throughout the COVID-19 pandemic. This manuscript describes aims, methods and first results of COVID-PCD.

\section{Methods}

\section{Study objectives}

We set up an online surveillance system which collects essential epidemiological and clinical data in real-time directly from people with PCD and publishes continuously summarised results. The study aims to: 1) describe incidence of COVID-19 in people with PCD, symptoms, course of disease, duration of illness, treatments and outcomes; 2) identify risk factors for incidence and prognosis; 3) describe the impact of the pandemic on daily life and healthcare in people with PCD; and 4) assess patients' experiences, wishes and needs during the COVID-19 pandemic.

\section{Study design}

COVID-PCD is an international observational cohort study using anonymous online questionnaires to collect information directly from people with PCD (clinicaltrials.gov registration number: NCT04602481). It is a participatory research project where people who have PCD have an active role in all stages of research. The study was requested by PCD support groups from Switzerland, Germany, the UK, the USA and Australia and set up in collaboration with a study team at the University of Bern, Switzerland, and the University of Southampton, UK. The study is designed for three age groups: children below 14 years, adolescents between 14 and 17 years, and adults aged 18 years or more. For children, the questionnaires are addressed to the parents, but the child is encouraged to help complete the questionnaires. Adolescents complete the questionnaires themselves. The study is currently available in English, German and Spanish with the possibility to expand to more languages.

\section{Inclusion criteria}

The study is addressed to people of any age from any country with a confirmed or suspected diagnosis of PCD. Eligibility of participants is assessed in the baseline questionnaire. We exclude people who answer "no" to both questions: "Have you been told by a doctor that you have PCD or are likely to have PCD?" 
and "Do you have a reason to believe that you have PCD, even though you have not received a diagnosis by a doctor?".

\section{Validating the diagnosis of PCD}

Diagnosing PCD is complex and requires several tests to be performed by an experienced team. Historically, patients may not have been diagnosed according to current standards [25] and in some patients, even experts are unable to confirm the diagnosis. We validate the diagnosis through questions asking the patients about results of the diagnostic tests. Many patients have received copies of their test results and can therefore report the type of tests they have had and their results. For the analysis, we can stratify the study population into people with a definite diagnosis, people with probable PCD and people with suspected PCD. During the study, we will further attempt to validate the diagnoses with original documents. We considered it important to have an inclusive approach and also allow people whose diagnosis is not proven into the study, because whether or not participants have a formal confirmation of PCD, they suffer from chronic lung disease and thus should be allowed to contribute their experiences.

\section{Recruitment of study participants}

The study is primarily advertised through PCD support groups (table 1) who contact and inform potential participating people with PCD through social media and e-mail networks and encourage them to take part in the study. The adverts include a link to the project website (www.covid19pcd.ispm.ch) which leads directly to the study information and registration. Initially, support groups from the UK (www.pcdsupport. org.uk), Germany (www.kartagener-syndrom.org/index.php), Switzerland, the USA and Canada (www. pcdfoundation.org), and Australia (www.pcdaustralia.org.au/) were involved, but more countries are joining as the study progresses. In regions of the world where PCD-specific patient support groups are lacking, healthcare specialists seeing people with PCD are asked to help inform patients about the study.

\section{Study procedures}

All aspects of the COVID-PCD study are online, including registration and consent and completing the baseline questionnaire, weekly questionnaires, information on hospitalisation and occasional thematic questionnaires (figure 1). The website includes detailed information about the study results and allows participants to register via a link that leads them directly into the study database. At first, participants are asked to enter their year of birth which directs them to the age-specific study information and questionnaires. Participants give digital consent to participate and are then asked to enter an e-mail address where the online questionnaires can be sent to. Immediately after the registration, participants receive an e-mail with the link to the baseline questionnaire. Adolescents are asked to also enter the e-mail address of a parent. The parent must give consent before the adolescent receives the baseline questionnaire. Participants must complete the baseline questionnaire to be enrolled in the study.

One week after completing the baseline questionnaire, and in weekly intervals thereafter, participants receive short follow-up questionnaires (figure 1). The follow-up questionnaire is not dependent on participants completing it every week; if participants miss one or more of the follow-up questionnaires, they will receive the links for the next ones. If a participant is hospitalised due to COVID-19, a link to an additional short questionnaire is sent. The study also allows thematic questionnaires that focus on specific topics related to the COVID-19 pandemic to be conceived and sent out. Participants and interested people can follow the progress of the study on the study website where information on number of recruited participants, incident COVID-19 infections and selected results from the questionnaires are uploaded regularly.

\section{TABLE 1 Collaborating primary ciliary dyskinesia (PCD) support organisations}

\begin{tabular}{|c|c|c|c|}
\hline PCD support organisation & Country & Contact persons & Website \\
\hline Selbsthilfegruppe Primäre Ciliäre Dyskinesie & Switzerland & Bernhard Rindlisbacher & \\
\hline Verein Kartagener-Syndrom und PCD & Germany & Hansruedi Silberschmidt & www.kartagener-syndrom.org/index.php/verein \\
\hline PCD Family Support Group UK & UK & Lucy Dixon & www.pcdsupport.orq.uk \\
\hline PCD Foundation & USA and Canada & Michele Manion & www.pcdfoundation.org \\
\hline PCD Australia Primary Ciliary Dyskinesia & Australia & Catherine Kruljac & www.pcdaustralia.org.au/ \\
\hline $\begin{array}{l}\text { Associazione Italiana Discinesia Ciliäre } \\
\text { Primaria Sindrome di Kartagener Onlus }\end{array}$ & Italy & Letizia Andolfi, Sara Bellu & www.pcdkartagener.it/associazione/ \\
\hline
\end{tabular}




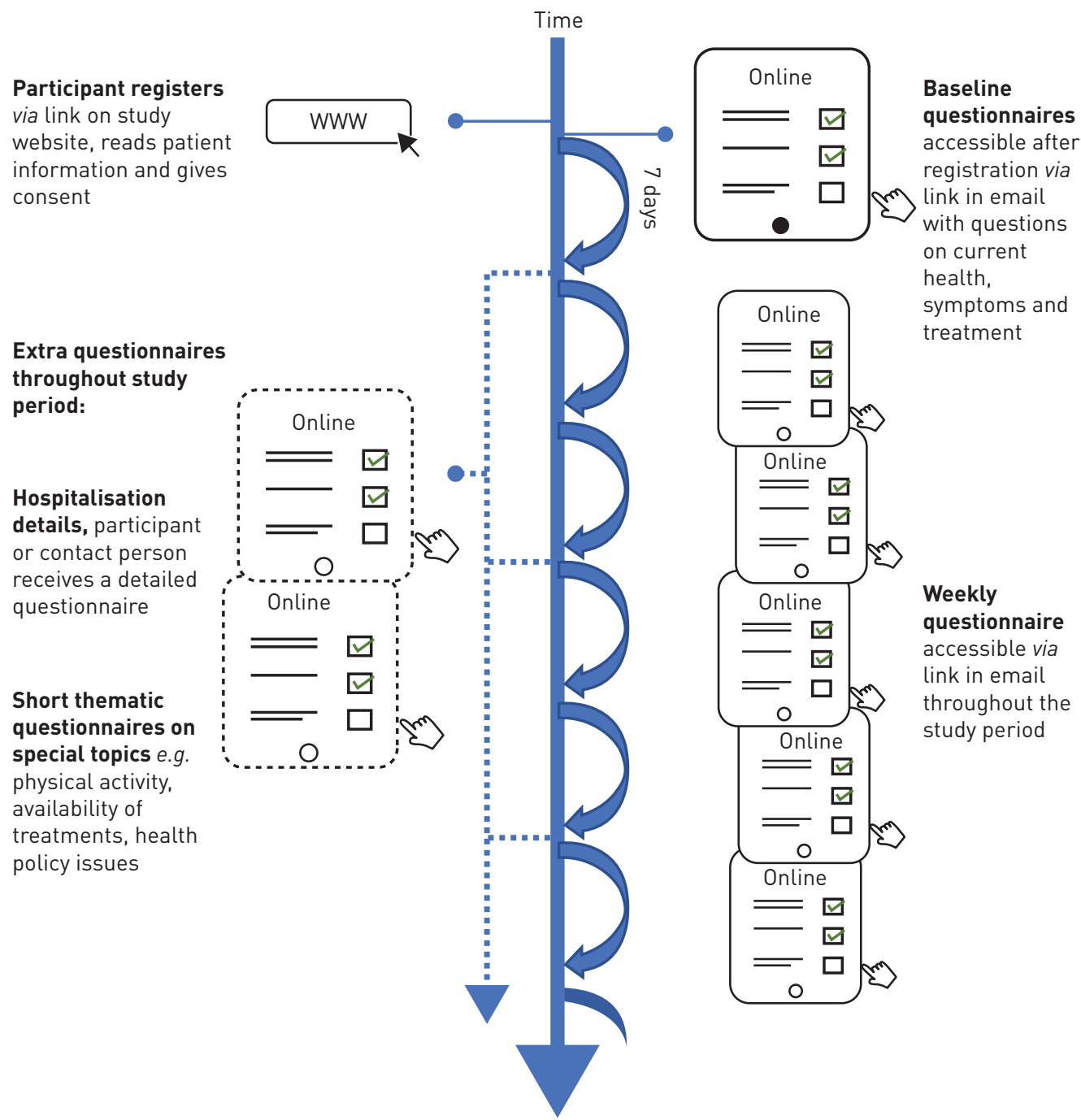

FIGURE 1 Timeline and follow-up procedures of the coronavirus disease 2019 (COVID-19) and primary ciliary dyskinesia (PCD) study.

\section{Information collected}

The baseline questionnaire aims to assess whether the participant has PCD, how the disease was diagnosed, what the person's usual symptoms are how severe the disease is, and how it is treated. It also aims to collect information on the social and environmental context such as people living in the same household, school and work environment, and physical activity. The baseline questionnaire is divided into four modules (table 2). Module 1 collects demographic data, contact information and information on SARS-CoV-2 infections that have occurred prior to study entry. Module 2 collects information on PCD diagnosis and baseline disease status. Module 3 asks about regular PCD-related symptoms, and module 4 collects information on work, education, lifestyle and health behaviours. Module 3 and 4 are based on the FOLLOW-PCD questionnaire [26].

The weekly follow-up questionnaire collects information on symptoms and incident SARS-CoV-2 infections, physical activity and time-varying lifestyle factors such as social contacts. If a participant has no symptoms, the weekly follow-up questionnaire is short. If a participant has symptoms, extra questions appear asking details about tests for SARS-CoV-2 and other infections, symptoms duration, healthcare contacts and medication taken.

A short questionnaire is sent in the event of a hospitalisation due to COVID-19. It asks about duration of the hospitalisation, unit where the patient was treated, treatments and recommendations received after discharge. 
TABLE 2 Information collected in the coronavirus disease 2019 (COVID-19) and primary ciliary dyskinesia (PCD) study

\begin{tabular}{ll} 
Questionnaire & Timing of distribution \\
\hline $\begin{array}{c}\text { Registration } \\
\text { questionnaire } \\
\begin{array}{c}\text { Baseline } \\
\text { questionnaire }\end{array}\end{array}$ & At registration \\
\hline
\end{tabular}

\section{Follow-up} questionnaire

\section{Hospitalisation questionnaire Thematic} questionnaires
Weekly (period can be adapted)

If a participant is hospitalised

In irregular intervals as research questions arise

\section{Information collected}

Language, year of birth, consent to participate, e-mail address

Module 1: Demographic information (country, region); contact information in case of hospital stay; history of COVID-19 infection (tests, test results, severity of infection, symptoms, people in household who had a COVID-19 infection), other infections

Module 2: PCD diagnosed by a physician (study eligibility question), PCD in close family, prior diagnostic tests for PCD and test results (nasal nitric oxide, high-speed video microscopy, electron microscopy, genetic test), year of PCD diagnosis, situs inversus, congenital heart defect, bronchiectasis, infections (bacteria, viruses, fungi), lung function, height, weight, airway clearance therapy, physiotherapy, oxygen use, antibiotic treatments, hospital stays, flu vaccinations Comorbidities and their treatments including asthma, hypertension, diabetes, heart failure, primary immunodeficiency, cancer, inflammatory bowel disease, and stroke

Module 3 (adapted from the standardised FOLLOW-PCD patient questionnaire [26]): Current symptoms: Symptoms from nose or ears, hearing problems, headaches, snoring, coughing, coughing up mucus, wheezing, shortness of breath, chest pain, fever, general feeling of being unwell

Module 4 (adapted from the standardised FOLLOW-PCD patient questionnaire [26]): Employment/educational status, profession, days missed from work due to PCD, mode of transportation to work/school, highest level of education

Level of physical activity, types of sports/activities regularly performed, smoking status, number of cigarettes per day, years of smoking, year of quitting smoking, anyone else in household smoking, nutrition lappetite in last 3 months, additional drink supplements, other supplements), living conditions (type of home, number of bedrooms in home, access to garden/yard), change in living condition due to COVID-19 pandemic

Current symptoms (in the past 7 days)

Recent COVID-19 infections: Contact with health professional due to COVID-19 infection, medication taken in the past 7 days, change in usual therapies past 7 days

Contact behaviour in the past 7 days: Activities le.g. stayed at home, went grocery shopping, went out for exercise, went occasionally or regularly to workplace/ school, etc.), use of public transportation, possible to keep $2 \mathrm{~m}$ distance from other people during public transport/at work/at school, number of people having close contact with

Date of hospitalisation, hospital unit in which patient was treated, duration of hospital stays, treatments, recommendation after discharge

Potential topics: Availability of PCD treatments during COVID-19 pandemic, physical activity during COVID-19 pandemic, protection measures at schools and workplaces, e.g. masks, plastic face shields, gloves, etc., anxieties and fears related to the COVID-19 pandemic

Additional thematic questionnaires developed throughout the study focus on special topics related to the pandemic such as mask use, anxiety, home schooling of children, physical activity or availability of medications. PCD support organisations and study participants are encouraged to suggest special topics and participate in developing those questionnaires.

\section{Participant engagement}

Participants shape the study in a participatory approach and can influence all aspects of the study (table 3). They had a decisive role in study design and content of baseline questionnaire. As the study goes on, participants are encouraged to propose research questions and topics for extra questionnaires, help to make sure questions are written in a language that is easily understandable, advise on logistics such as how to approach affected people, and choose results for publication on the website. A patient advisory group from the European Lung Foundation (ELF) (www.europeanlung.org/en/) includes interested people who have PCD. The group meets to discuss the COVID-19 outbreak, the PCD-COVID study and questions relevant to people with $\mathrm{PCD}$. 


\section{TABLE 3 Participant involvement in the study}

\begin{tabular}{|c|c|}
\hline Study step & Inputs from PCD support groups \\
\hline \multirow[t]{2}{*}{ Concept and design of study } & The idea for the study came from PCD support groups \\
\hline & $\begin{array}{l}\text { The study design was developed in close communication between PCD } \\
\text { support groups and the study team }\end{array}$ \\
\hline \multirow[t]{2}{*}{ Questionnaire design } & $\begin{array}{l}\text { The content of the baseline and follow-up questionnaires was decided } \\
\text { based on ideas from PCD support group representatives, healthcare } \\
\text { staff and researchers }\end{array}$ \\
\hline & $\begin{array}{l}\text { Wording of the questionnaires was checked by PCD support group } \\
\text { representatives to ensure that the language was understandable and } \\
\text { meaningful for all }\end{array}$ \\
\hline Recruitment of participants & $\begin{array}{l}\text { Study participants are recruited using measures such as: } \\
\text { - PCD support groups social media post links to the study website } \\
\text { - E-mails to PCD support group members } \\
\text { - Presentations about the study at PCD support group meetings and in } \\
\text { newsletters }\end{array}$ \\
\hline $\begin{array}{l}\text { Choice and interpretation of } \\
\text { results }\end{array}$ & $\begin{array}{l}\text { Summarised results displayed on the website are based on what is most } \\
\text { important for participants }\end{array}$ \\
\hline Thematic questionnaires & $\begin{array}{l}\text { Thematic questionnaires are developed based on suggestions from } \\
\text { participants and PCD support groups }\end{array}$ \\
\hline $\begin{array}{l}\text { Display of results on study } \\
\text { website }\end{array}$ & $\begin{array}{l}\text { Participants can suggest results to be posted on the website and how to } \\
\text { phrase them }\end{array}$ \\
\hline
\end{tabular}

\section{Study database and data protection}

The web-based database uses the Research Electronic Data Capture (REDCap) platform developed at Vanderbilt University (www.project-redcap.org) [27]. The database is hosted by the Swiss medical registries and data linkage centre (SwissRDL) at the University of Bern, Switzerland, and complies with all legal requirements for data security and data protection. Access to the database is regulated by a system with personal passwords. Only study team members who need to perform database management can access the database. Daily, weekly and monthly back-ups are performed and securely stored at the SwissRDL servers.

\section{Ethics}

The Bern Cantonal Ethics Committee (Kantonale Ethikkomission Bern) has approved this study (Study ID: 2020-00830). Informed consent to participate in the study is provided at registration into the study. Study participation is anonymous. Participants can withdraw their consent to participate at any time by contacting the study team.

\section{Current recruitment status}

The study started recruitment on April 30, 2020. By November 2, 2020, 556 people with PCD had completed the baseline questionnaire (figure 2). Together, participants have already completed a total of 4776 weekly questionnaires over a period of 23 weeks. On average, 50\% (range 33-68\%) of participants completed the weekly follow-up questionnaire (figure 2). The study includes people with PCD from 36 countries with the largest numbers from England $(n=121 ; 22 \%)$, the USA $(n=101 ; 18 \%)$, Germany $(n=78$; $14 \%)$ and Switzerland $(n=42,8 \%)$ (table 4). Two-thirds of participants are female $(n=340 ; 61 \%)$, and all age groups are well represented with $172(31 \%)<15$ years, $136(24 \%)$ aged 15 to 29 years, $154(28 \%)$ between 30 and 49 years, and 94 (17\%) being 50 years or older.

\section{Discussion}

The COVID-PCD study is an online surveillance system of COVID-19 in people with PCD which collects essential information in real-time directly from people with PCD. It is a participatory research project where people who have PCD have an active role in all stages of research. Summarised results are published continuously on the website and shared on social media via the PCD support groups to inform participants, researchers and physicians.

\section{Comparison with other studies}

To our knowledge, very few studies investigate the effect of COVID-19 on people with a rare disease and very few focus on respiratory diseases. A questionnaire survey from the rare diseases clinical research 


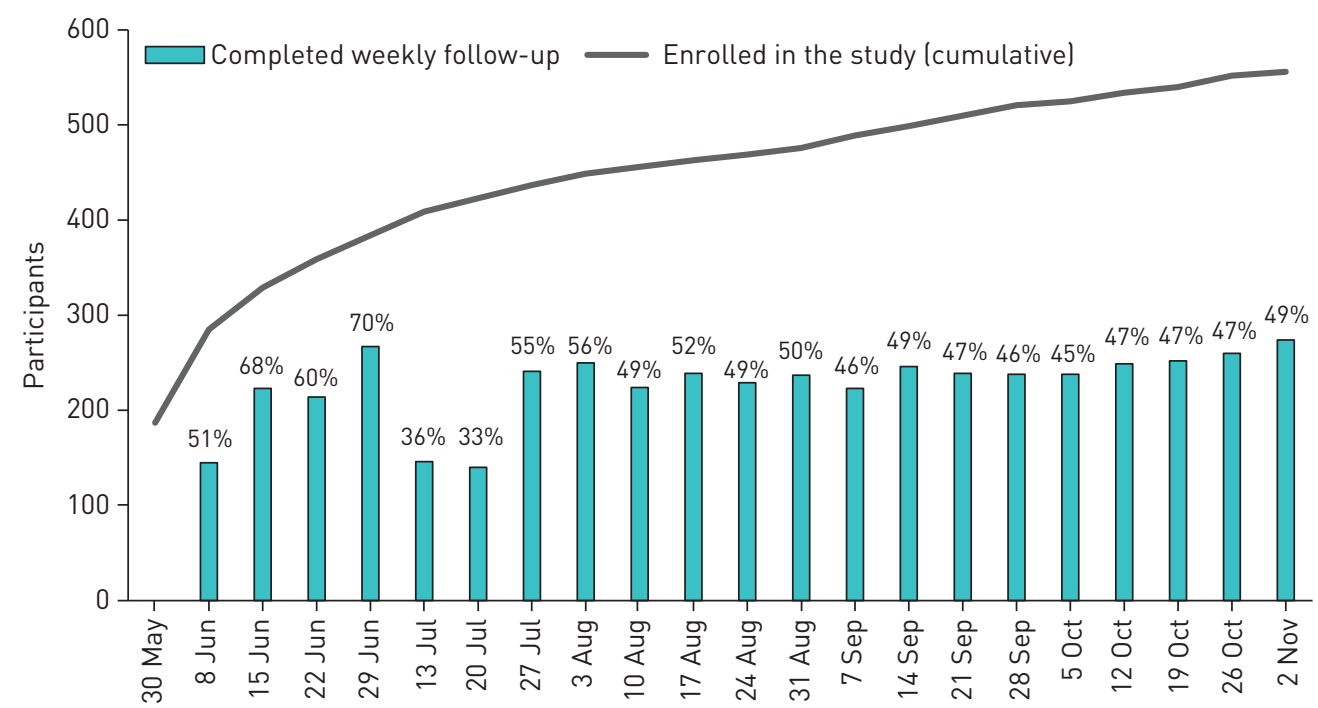

FIGURE 2 Number of people with primary ciliary dyskinesia (PCD) who enrolled in the study by November 2 , 2020 (cumulative) and number and per cent who completed the weekly follow-up questionnaire.

network based in Ohio, USA, collects cross-sectional information on the effect of COVID-19 from people with all types of rare diseases [28]. A major strength of this study is that recruitment is not happening through healthcare facilities, but any person with a rare disease and access to the internet can participate via a link on the study website. This also ensures that people with mild disease or limited access to healthcare may participate. However, the study is limited to the USA; the questionnaire is short and collects information only once, and it remains general as it includes people with any kind of rare diseases. Another research project, the ImmunoCOVID19 study, at the University of Southampton, UK, monitors COVID-19 in children with primary or secondary immunosuppression (below 18 years) [29]. Recruitment happens through hospitals. Participants complete a short baseline questionnaire and are followed up weekly through a short online questionnaire. This study follows participants longitudinally, which makes it fit for studying incidence of COVID-19 and study symptoms and prognosis. Other studies on people with

\section{TABLE 4 Country of residence and sex of participants, displayed in total and by age groups} $(n=556)$

Total $\quad 0-14$ years $15-29$ years $\quad 30-49$ years 50 years and above

$\begin{array}{lccccc}\begin{array}{l}\text { Subjects } \mathbf{n} \\ \text { Country }\end{array} & 556 & 172 & 136 & 154 & 94 \\ \quad \text { England } & 121(22) & 34(20) & 32(24) & 36(23) & 19(20) \\ \text { USA } & 101(18) & 35(20) & 23(17) & 26(17) & 17(18) \\ \text { Germany } & 78(14) & 34(20) & 9(7) & 21(14) & 14(15) \\ \text { Switzerland } & 42(8) & 8(5) & 16(12) & 5(3) & 13(14) \\ \text { Australia } & 27(5) & 11(6) & 5(4) & 5(3) & 6(6) \\ \text { Italy } & 22(4) & 7(4) & 6(4) & 9(6) & 0 \\ \text { Canada } & 20(4) & 7(4) & 3(2) & 6(4) & 4(2) \\ \text { The Netherlands } & 18(3) & 2(1) & 8(6) & 5(3) & 3(3) \\ \text { Scotland } & 12(2) & 4(2) & 3(2) & 3(2) & 2(2) \\ \text { Denmark } & 10(2) & 1(1) & 4(3) & 2(1) & 3(3) \\ \text { France } & 10(2) & 3(2) & 2(1) & 2(1) & 3(3) \\ \text { Norway } & 10(2) & 2(1) & 0 & 6(4) & 2(2) \\ \text { Other European countries } & 60(11) & 14(8) & 19(14) & 22(14) & 5(5) \\ \text { Other non-European countries } & 25(4) & 10(6) & 6(4) & 6(4) & 3(3) \\ \text { Sex (n=555) } & & & & & \\ \text { Male } & 214(39) & 92(53) & 49(36) & 41(27) & 32(34) \\ \text { Female } & 340(61) & 80(47) & 86(63) & 113(73) & 61(66) \\ \text { Other } & 1(0) & 0 & 1(1) & 0 & 0 \\ \end{array}$

Data are presented as $n(\%) .{ }^{\#}$ : countries with $n \geqslant 10$ displayed in table, countries with $n<10$ were categorised into other European countries and other non-European countries. 
rare respiratory diseases use data from hospital records. The European Cystic Fibrosis Society set up the COVID-CF project in Europe where data from national cystic fibrosis (CF) registries are pooled to identify people with CF who have been infected with SARS-CoV-2 [30, 31]. By October 4, 144 cases of COVID-19 in patients with CF were documented in 18 countries. A study in Spain investigated incidence of SARS-CoV-2 from March to May 2020 in 2500 CF patients registered in the national registry using information from hospital records [32]. However, these studies only identify the most severe cases of SARS-CoV-2 infections that result in hospitalisations. Mild cases are missed, and this type of study biases the results towards more severe infections.

\section{Strengths and limitations}

A key feature and major strength of this study is the participatory approach where people with PCD together with the team of researchers shape the study, recruit participants, and interpret and decide which results should be presented on the study website. The close collaboration between people with PCD and researchers ensures the relevance for participants and makes sure that study material is meaningful for people with PCD. It may also positively influence response rate in the weekly follow-up questionnaires. Another strength is the web-based study design, which allows participants to contribute their data to the database in real-time. This limits the risk of recall bias as participants only report symptoms from the last 7 days, and there is no delay caused by data entry as participants enter data themselves into the database. The PCD support groups provided essential inputs to the study questionnaires and study design. The broad inclusion criteria allowing people of any age from anywhere in the world to participate is another strength of the study. The COVID-PCD study is one of the largest international studies including data reported directly from people with a rare disease. COVID-PCD not only covers infection rates, severity of symptoms and prognosis of COVID-19 but also studies factors related to the COVID-19 pandemic such as social isolation and physical activity habits. Additionally, special topics can be studied at short notice using extra questionnaires that are sent out once and can be proposed by participants themselves.

One limitation of the study is the convenience sampling method. It is difficult to estimate the response rate without information on how many people with PCD have seen the study information, and it is difficult to know if the study participants are representative of the average population of people with PCD.

\section{Conclusion}

The COVID-19 pandemic evolves quickly and gathering data fast on how COVID-19 affects people with rare chronic diseases is essential for informing patients, physicians and policy makers. First results on recruitment from the COVID-PCD study show a good representation from many regions in the world across all age groups. COVID-PCD is an essential resource to follow people with PCD throughout the COVID-19 pandemic, help empower patients and in providing a platform for communication between patients, physicians and researchers.

Acknowledgements: We thank all participants and their families, and we thank the primary ciliary dyskinesia support groups and physicians who have advertised the study. We would like to thank Helena Koppe, Maria Christina Mallet and Dominique Rubi, University of Bern, for helping to set up the COVID-PCD database.

COVID-PCD patient advisory group (in alphabetical order): Sara Bellu, Associazione italiana Discinesia Ciliäre Primaria Sindrome di Kartagener, Onlus, Italy; Fiona Copeland, PCD Family Support Group, UK; Katie Dexter, PCD Family Support Group, UK; Lucy Dixon, PCD Family Support Group, UK; Susanne Grieder, Selbsthilfegruppe Primäre Ciliäre Dyskinesie, Switzerland; Catherine Kruljac, PCD Australia Primary Ciliary Dyskinesia, Australia; Michelle Manion, PCD Foundation, USA; Bernhard Rindlisbacher, Selbsthilfegruppe Primäre Ciliäre Dyskinesie, Switzerland; Hansruedi Silberschmidt, Verein Kartagener-Syndrom und PCD, Switzerland.

Author contributions: C.E. Kuehni, E. Pedersen, B. Rindlisbacher, J.S. Lucas, M. Goutaki, F. Copeland, H. Silberschmidt, A. Harris and M. Manion designed the study. E.S.L. Pedersen, E.N.R. Collaud, R. Mozun, Y.T. Lam, C Ardura-Garcia and M. Goutaki built the database and collected data. E.S.L. Pedersen drafted the manuscript. All authors contributed to iterations and approved the final version.

Conflict of interest: None declared.

Support statement: This research was funded by the Swiss National Foundation (SNF 320030B_192804/1); the PCD Foundation, USA; the Verein Kartagener Syndrom und Primäre Ciliäre Dyskinesie, Germany; and the PCD Family Support Group, UK. Study authors participate in the BEAT-PCD clinical research collaboration, supported by the European Respiratory Society. Funding information for this article has been deposited with the Crossref Funder Registry.

\section{References}

1 Wu Z, McGoogan JM. Characteristics of and important lessons from the coronavirus disease 2019 (COVID-19) outbreak in China: summary of a report of 72314 cases from the Chinese Center for Disease Control and Prevention. JAMA 2020; 323: 1239-1242. 
2 Verity R, Okell LC, Dorigatti I, et al. Estimates of the severity of coronavirus disease 2019: a model-based analysis. Lancet Infect Dis 2020; 20: 669-677.

3 Jutzeler CR, Bourguignon L, Weis CV, et al. Comorbidities, clinical signs and symptoms, laboratory findings, imaging features, treatment strategies, and outcomes in adult and pediatric patients with COVID-19: a systematic review and meta-analysis. Travel Med Infect Dis 2020; 37: 101825.

4 Chen N, Zhou M, Dong X, et al. Epidemiological and clinical characteristics of 99 cases of 2019 novel coronavirus pneumonia in Wuhan, China: a descriptive study. Lancet 2020; 395: 507-513.

5 Zhou F, Yu T, Du R, et al. Clinical course and risk factors for mortality of adult inpatients with COVID-19 in Wuhan, China: a retrospective cohort study. Lancet 2020; 395: 1054-1062.

6 Richardson S, Hirsch JS, Narasimhan M, et al. Presenting characteristics, comorbidities, and outcomes among 5700 patients hospitalized with COVID-19 in the New York City Area. JAMA 2020; 323: 2052-2059.

7 Størdal K, Bakken IJ, Greve-Isdahl M, et al. SARS-CoV-2 in children and adolescents in Norway: confirmed infection, hospitalisations and underlying conditions. Tidsskr Nor Laegeforen 2020; 140: 1-9.

8 Huang Y, Tan C, Wu J, et al. Impact of coronavirus disease 2019 on pulmonary function in early convalescence phase. Respir Res 2020; 21: 163.

9 Mo X, Jian W, Su Z, et al. Abnormal pulmonary function in COVID-19 patients at time of hospital discharge. Eur Respir J 2020; 55: 2001217.

10 Shapiro AJ, Davis SD, Ferkol T, et al. Laterality defects other than situs inversus totalis in primary ciliary dyskinesia: insights into situs ambiguus and heterotaxy. Chest 2014; 146: 1176-1186.

11 Bequignon E, Dupuy L, Zerah-Lancner F, et al. Critical evaluation of sinonasal disease in 64 adults with primary ciliary dyskinesia. J Clin Med 2019; 8: 619.

12 Goutaki M, Meier AB, Halbeisen FS, et al. Clinical manifestations in primary ciliary dyskinesia: systematic review and meta-analysis. Eur Respir J 2016; 48: 1081-1095.

13 Rubbo B, Best S, Hirst RA, et al. Clinical features and management of children with primary ciliary dyskinesia in England. Arch Dis Child 2020; 105: 724-729.

14 Frija-Masson J, Bassinet L, Honore I, et al. Clinical characteristics, functional respiratory decline and follow-up in adult patients with primary ciliary dyskinesia. Thorax 2017; 72: 154-160.

15 Kouis P, Goutaki M, Halbeisen FS, et al. Prevalence and course of disease after lung resection in primary ciliary dyskinesia: a cohort \& nested case-control study. Respir Res 2019; 20: 212.

16 Kinghorn B, McNamara S, Genatossio A, et al. Comparison of multiple breath washout and spirometry in children with primary ciliary dyskinesia and cystic fibrosis and healthy controls. Ann Am Thorac Soc 2020; 17: 1085-1093.

17 Halbeisen FS, Goutaki M, Spycher BD, et al. Lung function in patients with primary ciliary dyskinesia: an iPCD Cohort study. Eur Respir J 2018; 52: 1801040.

18 Halbeisen FS, Jose A, de Jong C, et al. Spirometric indices in primary ciliary dyskinesia: systematic review and meta-analysis. ERJ Open Res 2019; 5: 00231-2018.

19 Shah A, Shoemark A, MacNeill SJ, et al. A longitudinal study characterising a large adult primary ciliary dyskinesia population. Eur Respir J 2016; 48: 441-450.

20 Ardura-Garcia C, Goutaki M, Carr SB, et al. Registries and collaborative studies for primary ciliary dyskinesia in Europe. ERJ Open Res 2020; 6: 00005-2020.

21 Whicher D, Philbin S, Aronson N. An overview of the impact of rare disease characteristics on research methodology. Orphanet J Rare Dis 2018; 13: 14

22 Young K, Kaminstein D, Olivos A, et al. Patient involvement in medical research: what patients and physicians learn from each other. Orphanet J Rare Dis 2019; 14: 21.

23 de Blieck EA, Augustine EF, Marshall FJ, et al. Methodology of clinical research in rare diseases: development of a research program in juvenile neuronal ceroid lipofuscinosis (JNCL) via creation of a patient registry and collaboration with patient advocates. Contemp Clin Trials 2013; 35: 48-54.

24 Abma TA. Patients as partners in a health research agenda setting: the feasibility of a participatory methodology. Eval Health Prof 2006; 29: 424-439.

25 Lucas JS, Barbato A, Collins SA, et al. European Respiratory Society guidelines for the diagnosis of primary ciliary dyskinesia. Eur Respir J 2017; 49: 1601090.

26 Goutaki M, Papon JF, Boon M, et al. Standardised clinical data from patients with primary ciliary dyskinesia: FOLLOW-PCD. ERJ Open Res 2020; 6: 00237-2019.

27 Harris PA, Taylor R, Thielke R, et al. Research electronic data capture (REDCap): a metadata-driven methodology and workflow process for providing translational research informatics support. J Biomed Inform 2009; 42: 377-381.

28 Rare Diseases Clinical Research Network. Research survey for rare disease patients and their families about impacts of COVID-19. United States 2020. www.rarediseasesnetwork.org/covidsurvey Date last accessed: October 4, 2020; date last updated: October 4, 2020.

29 Southampton University. Clinical Research in Southampton. ImmunoCOVID19 study. www.uhs.nhs.uk/ ClinicalResearchinSouthampton/Public-and-patients/Featured-research-studies/Featured-research-

ImmunoCOVID19-study.aspx Date last accessed: October 19, 2020; date last updated: October 19, 2020.

30 Cosgriff R, Ahern S, Bell SC, et al. A multinational report to characterise SARS-CoV-2 infection in people with cystic fibrosis. J Cyst Fibros 2020; 19: 355-358.

31 European Cystic Fibrosis Society. COVID-CF project in Europe. 2020. www.ecfs.eu/covid-cf-project-europeDate last accessed: October 4, 2020; date last updated: October 4, 2020.

32 Mondejar-Lopez P, Quintana-Gallego E, Giron-Moreno RM, et al. Impact of SARS-CoV-2 infection in patients with cystic fibrosis in Spain: incidence and results of the national CF-COVID19-Spain survey. Respir Med 2020 170: 106062 . 